\title{
Editorial
}

\section{Introducing PRISMA as a requirement}

Advances in biomedical research in recent decades have led to tangible improvements in medical knowledge and practice and have contributed to better human health in general. As investment in biomedical research grows, so does research output. Although the biomedical research enterprise enjoys a great level of trust by consumers, policy makers and patients, this trust should not be taken for granted. Various reports have raised concerns over the quality of biomedical research and its potential to produce benefits to society at large ${ }^{(1)}$. There is no reason to believe that the situation is different in public health nutrition.

Poor reporting of research findings can lead to erroneous conclusions and is one example of how 'time and resources invested in the conduct of research' can be wasted. But journals can take clear actions to help reduce the waste ${ }^{(2)}$. Journals, and their editors, are responsible for ensuring that the manuscripts they publish include the information necessary for readers to justify the study, understand how it was conducted, and interpret the findings in light of the strengths and limitations of the study.

\section{New requirement for systematic reviews and meta-analyses submitted to Public Healtb Nutrition}

Systematic reviews and meta-analyses (SRMA) serve a special function in the published scientific literature, as they summarize the current state of understanding and evidence on a given topic and identify gaps in knowledge. Public Health Nutrition has always endorsed use of the PRISMA (Preferred Reporting Items for Systematic Reviews and Meta-Analyses) guidelines for SRMA (www. prisma-statement.org/). From September 2015 onwards, however, this endorsement becomes a requirement: authors submitting SRMA will be required to submit the completed PRISMA checklist along with the manuscript. This requirement excludes narrative reviews, but it will apply to all systematic reviews, including systematic reviews of observational studies.

The checklist is meant to serve as a resource to help authors improve the quality of their reporting, and to help reviewers and editors during the review process. It should be emphasized that the number of items checked off on the checklist is not to be used as a metric to assess the quality of a study, or to accept or reject a paper. Misuse of reporting guidelines in this regard has been raised as an issue in the past ${ }^{(3)}$. We recognize that there are legitimate circumstances in which items cannot be checked off; in these instances, authors will be asked to provide an explanation.

\section{Will it make a difference?}

We adopt this new policy at a time when maintaining the quality of both the peer review process and the SMRA being published is becoming more important. The number of SRMA published in Public Health Nutrition over the two-year period from 1 July 2013 to 30 June 2015 was twenty-eight, a 2.5-fold increase over the previous two years. At the same time, the total number of submissions has increased by about $40 \%$ and the peer review process has consequently become more selective.

Adopting the requirement comes with some concerns. It could deter submissions, possibly even the submission of more novel work. Also, although some studies have indicated that using reporting guidelines can improve the quality of research manuscripts ${ }^{(4-8)}$, the improvement may be quite modest. It is possible that many authors already use available checklists as guidelines even if not specifically required for submission. Thus, questions still to be considered on our part are whether the requirement will improve the quality of reviews published in Public Health Nutrition, and the extent to which authors, reviewers and editors find the checklist helpful. These questions will be the focus of an evaluation to be conducted by our Editorial Board and staff over the next 1-2 years. Findings from this assessment will serve as a basis for future decisions regarding checklist requirements as part of the journal's policy. Among the decisions is whether to recommend the use of other reporting guidelines that are available to help improve completeness of reporting (http://www.equatornetwork.org/).

In short, we hope this requirement will help us achieve two aims: (i) to improve the quality of the reviews being published; and (ii) to improve transparency in the peer review process. Ultimately, we hope that the mandatory use of the checklist for research papers will improve the quality of research manuscripts received, improve the peer review process, increase confidence in published research, and facilitate the uptake and implementation of research findings.

Carl Lachat Allison Hodge Stefanie Vandevijvere Eduardo Villamor Deputy Editors

Marilyn Tseng Editor-in-Chief 


\section{References}

1. Chalmers I, Bracken MB, Djulbegovic B et al. (2014) How to increase value and reduce waste when research priorities are set. Lancet 383, 156-165.

2. Glasziou P, Altman DG, Bossuyt P et al. (2014) Reducing waste from incomplete or unusable reports of biomedical research. Lancet 383, 267-276.

3. da Costa BR, Cevallos M, Altman DG et al. (2011) Uses and misuses of the STROBE statement: bibliographic study. BMJ Open 1, e000048.

4. Moher D, Jones A, Lepage L et al. (2001) Use of the CONSORT statement and quality of reports of randomized trials: a comparative before-and-after evaluation. JAMA $\mathbf{2 8 5}$, 1992-1995.
5. Cobo E, Cortés J, Ribera JM et al. (2011) Effect of using reporting guidelines during peer review on quality of final manuscripts submitted to a biomedical journal: masked randomised trial. BMJ 343, d6783.

6. Willis BH \& Quigley M (2011) The assessment of the quality of reporting of meta-analyses in diagnostic research: a systematic review. BMC Med Res Methodol 11, 163.

7. Tunis AS, McInnes MD, Hanna R et al. (2013) Association of study quality with completeness of reporting: have completeness of reporting and quality of systematic reviews and meta-analyses in major radiology journals changed since publication of the PRISMA statement? Radiology 269, 413-426.

8. O'Leary JD \& Crawford MW (2013) Review article: reporting guidelines in the biomedical literature. Can J Anesth 60 , 813-821. 